\title{
Editorial
}

\section{La libertad de}

expresión

En El Salvador, la libertad de expresión ha tenido ganancias palpables desde la firma de los Acuerdos de Paz en 1992. Desde entonces, el ejercicio del periodismo y la expresión de la opinión por parte de los ciudadanos se ha beneficiado de la abolición de la censura oficial y de otras prácticas coercitivas que, en un pasado todavía reciente, se abatieron sobre los periodistas, comunicadores sociales y todos aquellos que hacían uso público de la palabra.

Hecha la salvedad anterior, la situación de la libertad de palabra en nuestro país todavía dista mucho de ser idónea. Pero, es precisamente a raíz de la emergencia nacional provocada por los sismos de principio de año, que su fragilidad se ha vuelto más visible. Desde enero, hemos venido percibiendo signos sumamente preocupantes de regresos a tiempos y conductas que todos creíamos ya superados.

La situación de la libertad de expresión del país es frágil por varias razones. Para comenzar, existen limitaciones de carácter legal. La misma Constitución de la República es todavía tímida a la hora de definir ese derecho. Explícitamente, lo limita de acuerdo a los intereses "del Estado" y autoriza la censura en el caso de espectáculos públicos. Por otra parte, tampoco la legislación obliga al Estado y a los funcionarios a hacer accesible información de carácter público. Aquí, a las deficiencias normativas, se suman prácticas negativas sumamente arraigadas entre quienes manejan la cosa pública: el carácter secreto del manejo de la información, la irresponsabilidad política, la ausencia de una cultura de rendir cuentas a la población, etc. 
Más decisiva es, sin embargo, la endeblez de las instituciones periodísticas, su poca autonomía, lo que las hace altamente vulnerables chantajes e intimidaciones de quienes detentap el poder político y económico. El gobierno, pese a las promesas del presidente en sentido contrario, todavía tiene como práctica premiar con la publicidad estatal a sus aliados políticos y a los medios dóciles a promover la "línea oficial". Pero su poder se extiende mucho más lejos. Por estar muchas veces turbiamente mezclados intereses estatales con intereses particulares, la publicidad comercial privada también se convierte en un instrumento de premio o castigo.

Esto quedó a la vista durante la reciente emergencia sísmica. El gobierno ha vuelto a la práctica de convocar a los propietarios de los principales medios de comunicación e instarles a colaborar con la estrategia de imagen no sólo gubernamental sino del partido en el gobierno. Muchos medios no sólo han reac:ionado pasivamente, es decir, mostrándose especialmente receptivos a quienes coinciden con la línea oficial; sino de manera activa, prestándose a montar campañas difamatorias en contra de rivales o disidentes de esta línea.

La casuística en este sentido es abultada. Baste recordar el caso que más impactó a la opinión pública durante el presente año: los ataques que TV 12 y su figura más reconocida, el periodista Mauricio Funes, recibieran como castigo por no haberse plegado a los llamados oficiales a la "unidad nacional". En una conferencia de prensa, el presidente Francisco Flores llegó incluso a denunciar la conducta "antipatriótica" del mentado canal televisivo medio y a acusarles de obstaculizar los esfuerzos de reconstrucción. Es de aclarar que el único pecado de TV 12 había sido simplemente apegarse a la conducta del periodismo responsable e independiente. Por ello, asumió una postura de vigilancia crítica a dos cuestiones de interés público y que la política de comunicaciones del gobierno habría de manejar desastrosamente: La tragedia de Las Colinas y el manejo de la ayuda humanitaria.

Como resultado de su "rebeldía", TV 12 sufrió el corte inmediato de una buena porción de la publicidad privada. Lo más grave es que esta medida derivó de un acuerdo tácito de la alianza entre el gobierno y la cúpula publicitaria y empresarial del país. Mauricio Funes, por su parte, se convirtió en blanco de ataques ad hominem por parte de El Diario de Hoy, matutino rotativo de gran circulación e influencia en la opinión pública, y su principal editorialista.

Se puede afirmar que esta serie de incidentes que pusieron a un medio de comunicación independiente al borde de la extinción han marcado el punto más bajo de la libertad de expresión de nuestro país desde la firma de los acuerdos de paz. Pero los signos preocupantes no dejan de manifestarse. Paradójicamente, un presidente que parecía en un primer momento haberse distanciado de las prácticas autoritarias y antidemocráticas de su partido, avala una política informativa que representa un claro retroceso con respecto a sus antecesores. Como en los tiempos de la guerra o de las dictaduras militares, desde Casa Presidencial 
se elaboran consignas de manipular la información para desprestigiar a los rivales políticos. Esto ocurrió durante algunas marchas de protestas y, más claramente, con motivo de celebración del Día del Trabajo. Allí los periodistas de varios medios de comunicación estuvieron a la caza de hechos aislados de violencia y los sacaron de proporción en sus reportajes con el afán de afectar la imagen del FMLN. A parte de la docilidad con que los principales medios de comunicación hacen juego a la estrategia publicitaria del gobierno, es de notar la reaparición de otras prácticas nefastas.

En los últimos años, los principales medios de noticias han dado pasos notables en profesionalismo e independencia en la cobertura. Un desarrollo notable ha sido el reportaje de investigación que, en muchos casos, ha defendido efectivamente los intereses de la comunidad al denunciar casos de corrupción y abuso de poder. Sin embargo, junto a esos positivos avances, vuelven a ponerse a la orden del día noticias donde la descalificación y la calumnia son regla. Como cjemplo, basta recordar el tratamiento totalmente sesgado e irresponsable que recientemente tuvieran, por parte de un medio rotativo, ciertas declaraciones Monscñor Rosa Chávez. El obispo auxiliar de San Salvador había hecho un llamado a la cordura a quienes condenaban el fallo de un jucz en un sonado caso de secuestros. Estc llamado a la cordura no era más que un recordatorio de la necesidad de respetar el debido proceso como parte esencial en el funcionamiento de las instituciones democráticas. Sin embargo, una reconocida periodista no se molestó en reproducir las declaraciones del líder religioso y no vaciló en lanzarle acusaciones c invectivas impropias del lenguaje y la ética profesional periodística.

Todos estos sucesos nos llevan a pensar que para abordar el problema de las condiciones del debate público en nuestro país no basta la tradicional categoría de ideología. No estamos simplemente así ante una visión de mundo que, por estar comprometida con ciertos intereses, percibe de manera parcial y distorsionada la realidad. A decir verdad, cuando alguien es sincero y honesto desde su perspectiva ideológica no representa ninguna amenaza a la libertad de expresión. Todo lo contrario, si las distintas posiciones ideológicas se expresaran de manera libre y honesta, mucho avanzaríamos en pos de la verdad. Pues no existe ningún punto ncutro desde donde la realidad se perciba exenta de toda deformación. Sin embargo, el problema de la ideologización que históricamente padeció nuestro país responde a estrategias de violencia simbólica mucho más burdas y descaradas, donde la intimidación, la manipulación descarada, la difamación y, especialmentc, la mentira cstán a la orden del día. Es urgente enfrentar el peligro del retorno de cstas prácticas. Si no somos capaces de conjurar este fantasma, poco habremos avanzado nuestra incursión por los senderos de la democracia habrá sido una débil ilusión. 